\title{
Erratum: Motivation, Social Emotion, and the Acceptance of Artificial Intelligence Virtual Assistants - Trust-Based Mediating Effects
}

\author{
Frontiers Production Office* \\ Frontiers Media SA, Lausanne, Switzerland
}

Keywords: Al virtual assistant, motivation, social emotion, trust, acceptance, mediating effects, inverted U relationship

OPEN ACCESS

Approved by:

Frontiers Editorial Office,

Frontiers Media SA, Switzerland

*Correspondence:

Frontiers Production Office

production.office@frontiersin.org

Specialty section:

This article was submitted to

Emotion Science,

a section of the journal

Frontiers in Psychology

Received: 06 October 2021 Accepted: 06 October 2021

Published: 26 October 2021

Citation:

Frontiers Production Office (2021)

Erratum: Motivation, Social Emotion,

and the Acceptance of Artificial

Intelligence Virtual

Assistants - Trust-Based Mediating Effects. Front. Psychol. 12:790448.

doi: 10.3389/fpsyg.2021.790448

\section{An Erratum on}

Motivation, Social Emotion, and the Acceptance of Artificial Intelligence Virtual Assistants-Trust-Based Mediating Effects

by Zhang, S., Meng, Z., Chen, B., Yang, X., and Zhao, X. (2021). Front. Psychol. 12:728495. doi: $10.3389 /$ fpsyg.2021.728495

Due to a production error, an incorrect funding statement was inserted into the article.

A correction has been made to the Funding section.

"This work was supported by the Social Science Foundation of Heilongjiang Province of China (18TQC239), Guangxi Science and Technology Plan Project (Guangxi Science and Technology Base and Talent Special Project: AD20159069)."

The publisher apologizes for this mistake. The original version of this article has been updated.

Publisher's Note: All claims expressed in this article are solely those of the authors and do not necessarily represent those of their affiliated organizations, or those of the publisher, the editors and the reviewers. Any product that may be evaluated in this article, or claim that may be made by its manufacturer, is not guaranteed or endorsed by the publisher.

Copyright $\odot 2021$ Frontiers Production Office. This is an open-access article distributed under the terms of the Creative Commons Attribution License (CC BY). The use, distribution or reproduction in other forums is permitted, provided the original author(s) and the copyright owner(s) are credited and that the original publication in this journal is cited, in accordance with accepted academic practice. No use, distribution or reproduction is permitted which does not comply with these terms. 